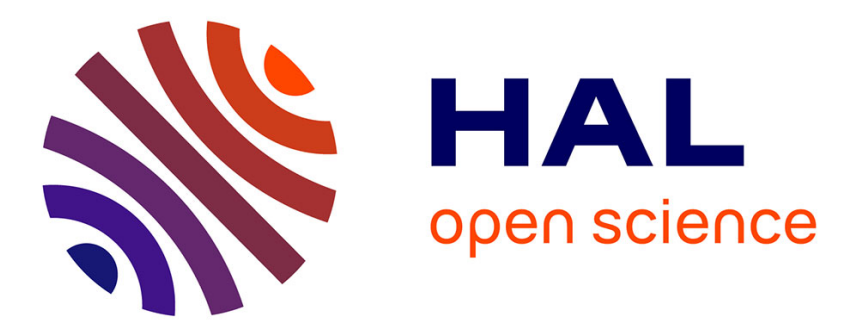

\title{
Ontology-Based Semantic Modeling for Automated Identification of Damage Mechanisms in Process Plants
}

\author{
Andika Rachman, R. M. Chandima Ratnayake
}

\section{To cite this version:}

Andika Rachman, R. M. Chandima Ratnayake. Ontology-Based Semantic Modeling for Automated Identification of Damage Mechanisms in Process Plants. 19th Working Conference on Virtual Enterprises (PRO-VE), Sep 2018, Cardiff, United Kingdom. pp.457-466, 10.1007/978-3-319-99127-6_39 . hal-02191200

\section{HAL Id: hal-02191200 \\ https://hal.inria.fr/hal-02191200}

Submitted on 23 Jul 2019

HAL is a multi-disciplinary open access archive for the deposit and dissemination of scientific research documents, whether they are published or not. The documents may come from teaching and research institutions in France or abroad, or from public or private research centers.
L'archive ouverte pluridisciplinaire HAL, est destinée au dépôt et à la diffusion de documents scientifiques de niveau recherche, publiés ou non, émanant des établissements d'enseignement et de recherche français ou étrangers, des laboratoires publics ou privés.

\section{(c)(1)}

Distributed under a Creative Commons Attribution| 4.0 International License 


\title{
Ontology-Based Semantic Modeling for Automated Identification of Damage Mechanisms in Process Plants
}

\author{
Andika Rachman and R. M. Chandima Ratnayake \\ University of Stavanger, N-4036 Stavanger, Norway \\ \{andika.r.yahya, chandima.ratnayake\}@uis.no
}

\begin{abstract}
Damage mechanisms reduce the ability of equipment to deliver its intended function and, thus, increase the equipment's probability of failure. Damage mechanism assessment is performed to identify the credible damage mechanisms of the equipment; thereby, appropriate measures can be applied to prevent failures. However, due to its high dependency on human cognition, damage mechanism assessment is error-prone and time-consuming. Additionally, due to its multi-disciplinary nature, the damage mechanism assessment process requires unambiguous communication and synchronization of perspectives among collaborating parties from different knowledge domains. Thus, the Damage Mechanism Identification Ontology (DMIO), supported by Web Ontology Language axioms and Semantic Web Rule Language rules, is proposed to conceptualize damage mechanism knowledge in both a human- and machine-interpretable manner and to enable automation of the damage mechanism identification task. The implementation of DMIO is expected to create a leaner damage mechanism assessment process by reducing the lead-time to perform the assessment, improving the quality of assessment results, and enabling more effective and efficient communication and collaboration among parties during the assessment process.
\end{abstract}

Keywords: Ontology $\cdot$ semantic model $\cdot$ artificial intelligence $\cdot$ damage mechanism $\cdot$ automation $\cdot$ cognitive system $\cdot$ lean $\cdot$ collaboration

\section{$1 \quad$ Introduction}

Damage mechanisms (DMs), such as corrosion and fatigue, relate to the process that diminishes the ability of process equipment to perform its intended function during operations [1]. DMs can lead to equipment failure and the release of hazardous substances, which is detrimental to the continuity of production and to the safety of personnel, society, and the environment [2]. Hence, DM assessment (DMA) becomes a critical task, to identify the relevant DMs in process equipment and to determine the appropriate mitigation technique and inspection method, in order to prevent catastrophic failure [3].

There are two main problems in performing DMA. The first is its tendency to be a time-consuming and error-prone task. The high number of items of equipment in a process plant and the complex interactions among factors that cause specific DM (e.g., material of construction and operating/environmental conditions) make DMA cumbersome and vulnerable to human error. Moreover, the DMA process highly depends on 
human cognition; thus, its results rely heavily on the assumptions, beliefs, and knowledge of the individuals who conduct the assessment [4]. Although industrial standards and company-specific guidelines exist to support the assessment [3], the lack of familiarity with these references may cause personnel to perform assessment based solely on their own knowledge and experience. Consequently, human biases and subjectivity are involved, causing the assessment results to vary from person to person.

The second problem concerns the multi-disciplinary nature of DMA domain knowledge. Various parties (e.g., materials/corrosion engineers, process engineers, contractors, etc.) collaborate on and contribute to the DMA process. However, there is a lack of methods which allow unambiguous communication and synchronization of perspectives among these collaborating parties. Consequently, different parties may develop their own terms to describe the same concept and semantic information [5], causing data mismatch and information inconsistency that hinder effective and efficient collaboration and information exchange [6].

The objective of this paper is to develop a DM identification ontology (DMIO) as a tool to tackle the aforementioned problems. The DMIO is an ontology-based semantic model that enables the conceptualization of DM knowledge in both a human- and machine-interpretable manner [7, 8]. Based on the DMIO, combinations of factors that affect the occurrence of certain DMs can be modeled into the Web Ontology Language (OWL) axioms and the Semantic Web Rule Language (SWRL) rules. This approach facilitates automated reasoning, to identify the relevant DMs based on the influencing factors and knowledge representation contained in the model. The application of DMIO is expected to create a leaner DMA process, by ensuring that the assessment is aligned with the specified guidelines, reducing the variability inherent in the assessment results, and reducing the overall lead-time to perform DMA.

Moreover, DMIO enables formalized communication within collaborating parties in the assessment process. DMIO provides structures for concepts in DMA domain knowledge that avoid semantic inconsistency and enable the effective and efficient collaboration of several disciplines and stakeholders in an overall DMA process [9]. It is a valuable tool for enabling unambiguous communication and the synchronization of perspectives among collaborating teams, as well as the interoperability and integration of tools and applications [10].

The remainder of this paper is organized as follows. Section 2 discusses the development process of DMIO. Sections 3 and 4 present the DMIO model and its implementation in Protégé. An illustrative example of DMIO implementation is given in Section 5 to demonstrate its utilization in a real case and to validate its functionality. Section 6 provides the discussion of the case study and section 7 concludes the paper.

\section{Development of Damage Mechanism Identification Ontology}

The ontology construction process used in this research is adapted from FernándezLópez, Gómez-Pérez and Juristo [11] (see Fig. 1). The main goal of the knowledge specification phase is to describe the purpose and scope of the ontology being developed [11]. The purpose of DMIO is to formalize DM knowledge in the process industries and to support automated DM identification. The scope of the ontology is static 
pressurized equipment (e.g., drums, filters, piping system, heat exchangers, etc.) in process plants. The DMA typically consists of three main steps: (1) data gathering, (2) DM identification, and (3) degradation rate estimation. The DMIO only covers the DM identification part of DMA.

\begin{tabular}{|c|c|c|c|c|}
\hline $\begin{array}{l}\text { Knowledge } \\
\text { Specification }\end{array}$ & $\begin{array}{l}\text { Knowledge } \\
\text { Acquisition }\end{array}$ & $\begin{array}{c}\text { Knowledge } \\
\text { Conceptualization }\end{array}$ & $\begin{array}{l}\text { Knowledge } \\
\text { Formalization }\end{array}$ & $\begin{array}{c}\text { SWRL Rule } \\
\text { Development }\end{array}$ \\
\hline
\end{tabular}

Fig. 1. The development process of DMIO

Knowledge acquisition involves identifying and elucidating relevant concepts in relation to the corresponding domain [11]. API 571 [12] and API 581[1], the industrial standards that contain valuable concepts for identifying DMs in the process industries, are selected as the main sources for knowledge acquisition.

The knowledge acquisition step generates unorganized knowledge in the form of terms (e.g., instances, concepts, verbs, attributes) [13]. The knowledge conceptualization phase then arranges these terms into a structured model that describes the corresponding domain [11].

All the concepts and their associated relations, attributes, and instances from the knowledge conceptualization step are codified into a formal language in the knowledge formalization step. OWL, the standard language for ontology construction, is used to formalize the knowledge. This is supported by Protégé 5.2.0, an open-source software for building intelligent systems, based on OWL language [14].

SWRL is embedded to enable expressivity (i.e., rules and logic) in OWL [15]. In this study, the rules and logic established in SWRL are based on API 571. API 571 contains two main sections: (1) general DMs that are applied in all process industries and (2) DMs applied only in the refining industries. This study focuses only on the first section of API 571. In total, $39 \mathrm{DMs}$ are coded into SWRL rules. In practice, API 571 is not used as the sole and final technical basis for DMA, but it is utilized in conjunction with the other related best practices and documentations [12].

\section{The Taxonomical Structure of Damage Mechanism Identification Ontology}

The DMIO represents the concepts, relations, attributes, and instances for performing DM identification in process plants. The DMIO, supported by OWL axioms and SWRL rules, becomes the foundation for automated DM identification in process plants. The visualization of DMIO is shown in Fig. 2. There are six main classes in the DMIO: the Equipment class, the DamageMechanism class, the MaterialClass class, the FluidStream class, the Unit class, and the Fuel class.

The Equipment class is central to the DMIO because the instances that undergo DMA comes from this class. The DamageMechanism class is related to the Equipment class through the hasDegradation property. The DamageMechanism class includes a set of damage mechanism types that affect equipment in the process plants, based on 
API 571. The MaterialClass is related to the Equipment class through hasMaterialOfConstruction property. The sub-classes of the MaterialClass represent the common material types used in the process plants.

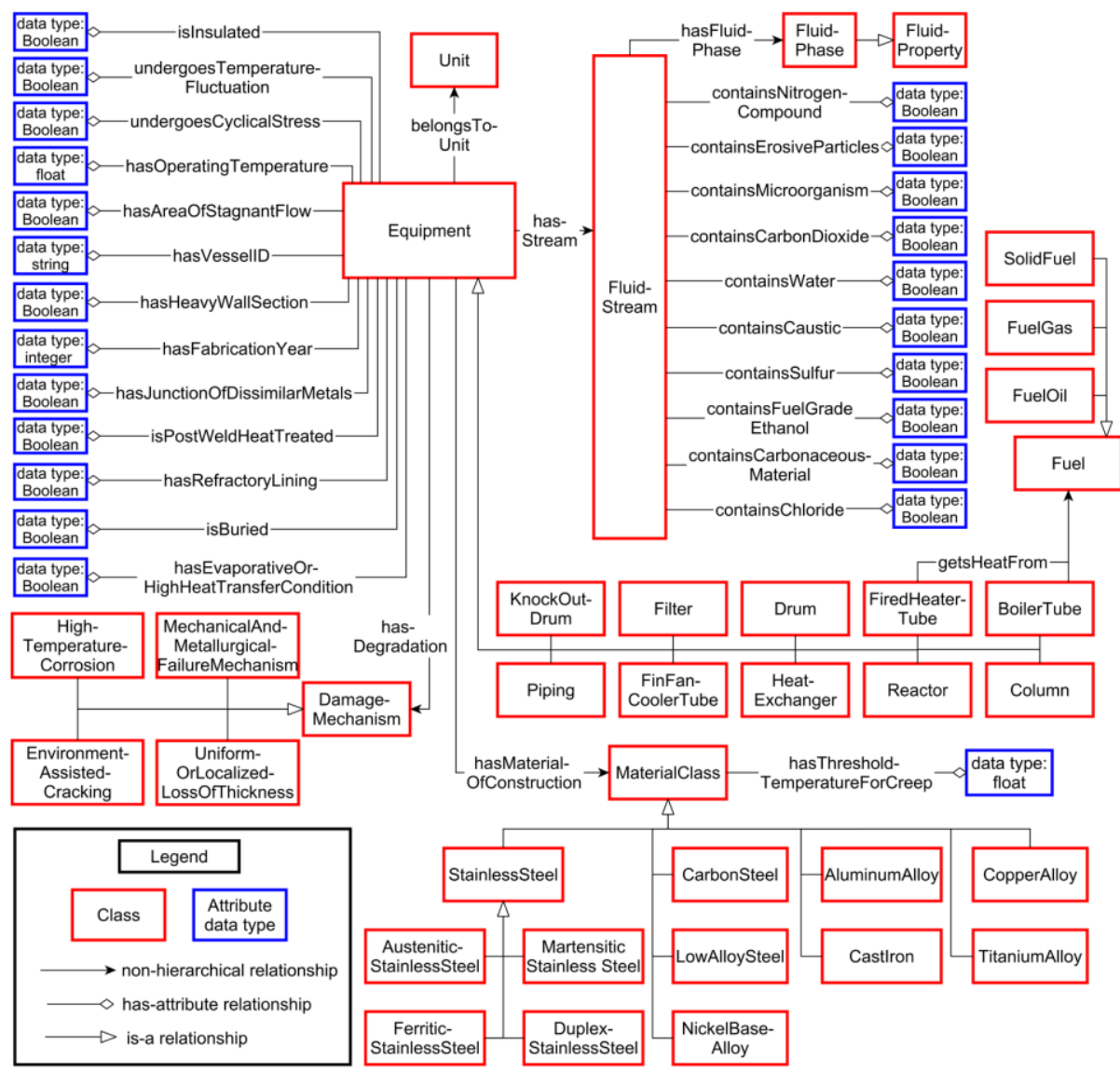

Fig. 2. The visualization of DMIO

The FluidStream class is connected to the Equipment class through hasStream property. This class embodies the actual fluid contained inside the equipment. The FluidStream is also related to the FluidPhase class, to indicate the phase of the fluid stream. The Unit class, related to the Equipment class through belongsToUnit property, represents the process unit where the equipment is situated. This class is included in the ontology because the occurrence of some DMs (e.g., cooling water corrosion and boiler water condensate corrosion) is specific to certain units.

The Fuel class is related to two subclasses of the Equipment class (i.e., FiredHeaterTube and BoilerTube) via the getsHeatFrom property. The fired heater tube and boiler tube require heat energy to heat their fluid containment, and the energy source comes from fuel. The exposure of the fired heater tube and boiler tube to the emission and combustion products of the fuel can generate certain DMs, such as flue-gas dew-point 
corrosion and fuel ash corrosion. That is the reason the Fuel class is only related to FiredHeaterTube and BoilerTube subclasses.

In addition to class relationships, attributes are used to depict factors that can be expressed by literals (shown by the blue boxes in Fig. 2). These attributes are numerical concepts (e.g., operating temperature) or parameters that can be addressed by true or false value (i.e., Boolean data type).

Based on the DMIO, a set of SWRL rules, founded on API 571, are defined to identify the DMs. An example of a SWRL rule for one of the DMs is shown in Fig. 3.

Corrosion Under Insulation (CUI) of carbon steel description based on API 571:

CUI is a type of external corrosion that occurs on insulated piping, pressure vessels, and structural components, due to the presence of trapped water under the insulation. Insulated piping and items of equipment made of carbon steel and those that are in intermittent service or operate between $-12^{\circ} \mathrm{C}$ and $175^{\circ} \mathrm{C}$ are susceptible to CUI.

SWRL Rule for CUI of carbon steel based on API 571 description:

Equipment(?e) ^ hasMaterial(?e, ?m) ^ CarbonSteel(?m)^ isInsulated(?e, true) ^ hasOperatingTemperature $(? e, ? t)^{\wedge}$ swrlb:greaterThanOrEqual(?t, -12.0)^swrlb:lessThanOrEqual(?t, 175.0) -> hasDegradation(?e, CorrosionUnderInsulation)

Fig. 3. An example SWRL rule for corrosion under insulation (CUI) of carbon steel

\section{Implementation in Protégé}

The implementation of OWL-based ontology and SWRL into Protégé is described as a system architecture, shown in Fig. 4.

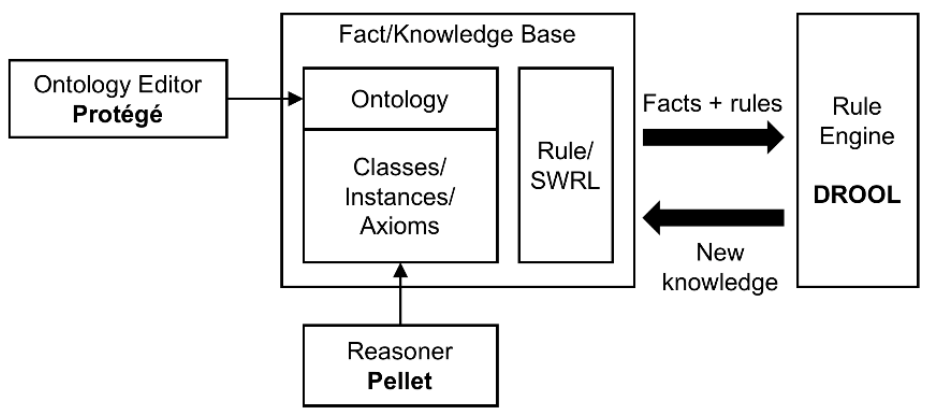

Fig. 4. Implementation environment of Protégé [16]

This system comprises four key components: (1) the ontology editor, (2) the reasoner, (3) the fact/knowledge base, and (4) the rule engine. Protégé serves as the ontology editor; i.e., it defines the ontology's classes, relations, attributes, axioms, and instances and puts them into a model that can be modified if necessary [16]. An excerpt of DMIO implementation in Protégé 5.2.0 is shown in Fig. 5. 


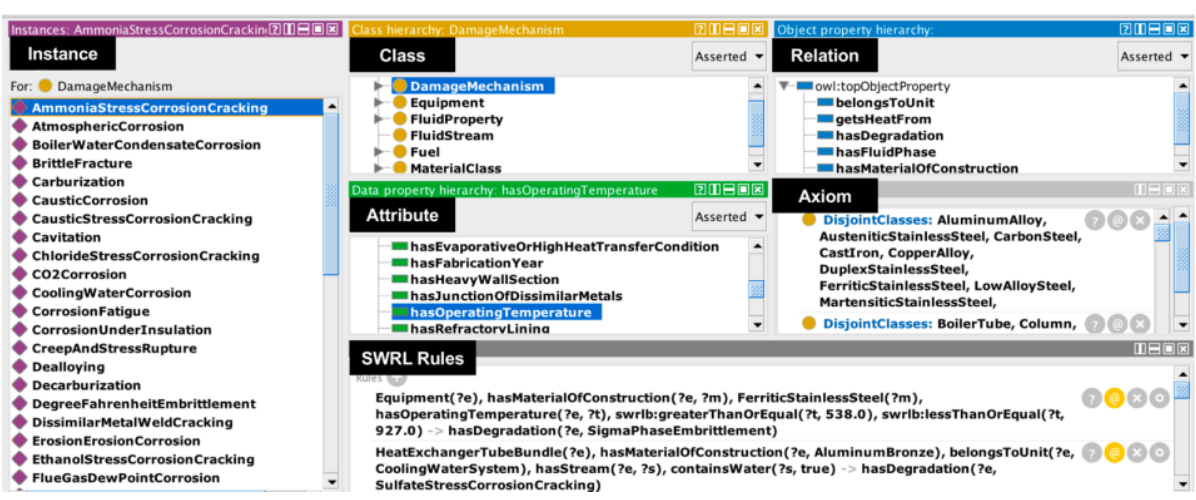

Fig. 5. An excerpt of DMIO implementation in Protégé

The reasoner provides the ontology editor with the capability to undertake automated classification and to check the consistency of the developed ontology [17]. In this study, Pellet is selected as the reasoner.

The fact/knowledge base contains the ontology and the SWRL rules. These facts and rules are passed to the DROOL rule engine, where they are combined and converted into new knowledge [16]. The generated new knowledge is then used to update the ontology.

\section{Case Study: Identification of Damage Mechanisms in Fractionating Column in a Refinery}

To demonstrate the utilization of DMIO and to validate its functionality in a real case, an illustrative example of the identification of DMs in a fractionating column in a refinery is given in this section. In refineries, a fractionating column is a part of the crude unit and is an essential piece of equipment for separating the incoming crude oil into its components parts, such as naphtha, light gas oil, heavy gas oil, and long residue.

\subsection{Design and Operating Data}

The schematic diagram, design data, and operating data of the fractionating column used as the case study are shown in Fig. 6. The fractionating column is not expected to undergo any cyclical stress or temperature fluctuation. No part of the column is buried, and no stagnant flow is expected inside it. The feed of the fractionating column is expected to contain some sulfur; other contaminants such as water and $\mathrm{CO}_{2}$ are considered negligible. Components such as nitrogen compounds, caustics, chlorides, and ethanol are non-existent. 
Automated Identification of Damage Mechanisms in Process Plants 447

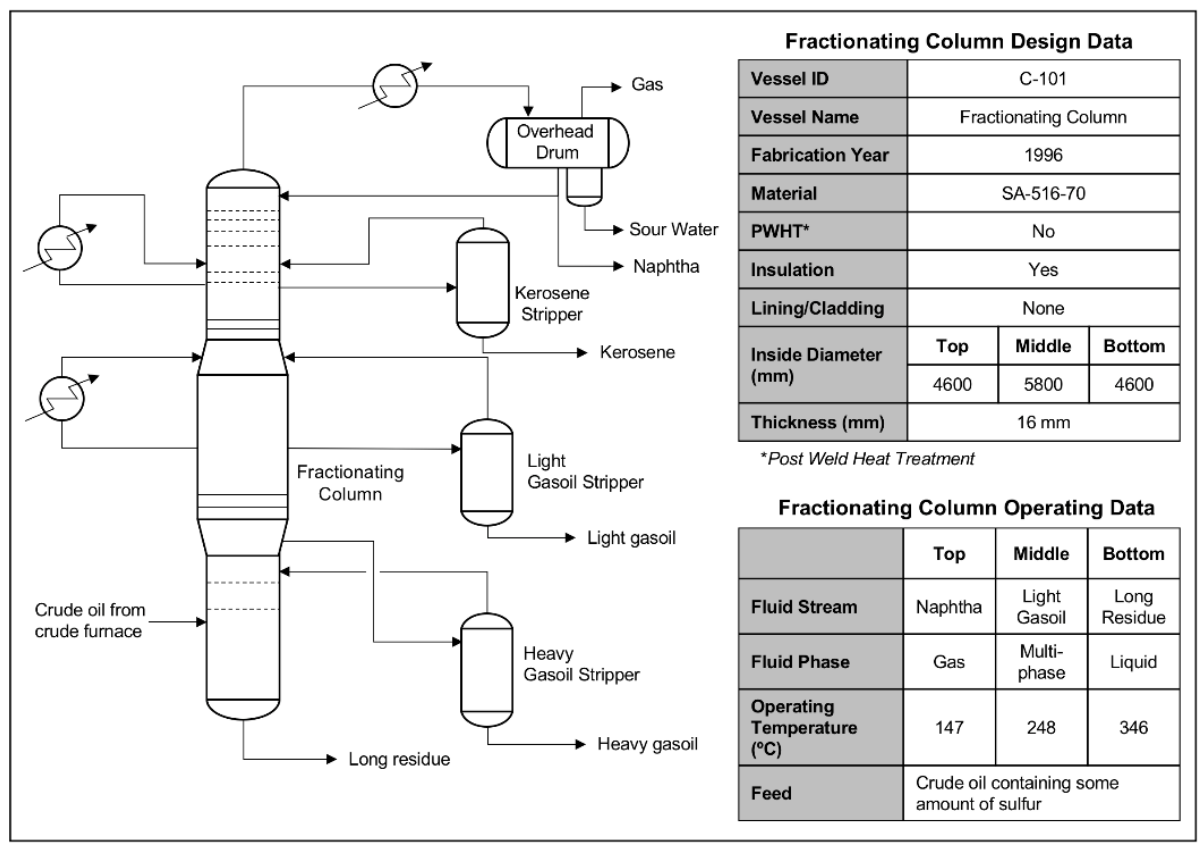

Fig. 6. The schematic diagram, design data, and operating data of the fractionating column

\subsection{Instance Generation}

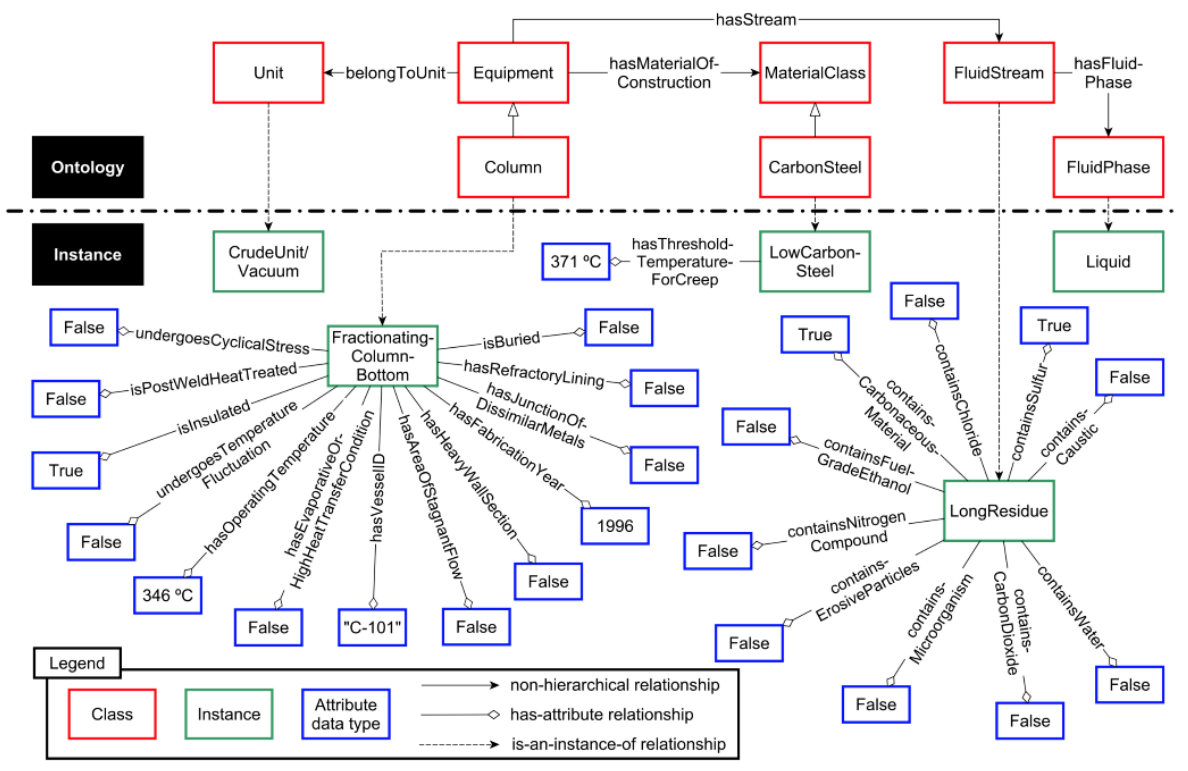

Fig. 7. DMIO instance generation for fractionating column bottom part 
Based on the aforementioned design and operating data, the instances related to DM identification for the fractionating column are generated. Because the fractionating column has different operating conditions in its top, middle, and bottom parts, three instances are generated for the fractionating column: FractionatingColumnTop, FractionatingColumnMiddle, and FractionatingColumnBottom. In this case study, only the FractionatingColumnBottom part is discussed.

The material of class construction of the fractionating column is SA-516-70. In the DMIO, the instances of the MaterialClass class are generalized, based on their general type. SA-516-70 is a type of low carbon steel, so it is modeled as a LowCarbonSteel instance under the CarbonSteel and MaterialClass class. An illustration of DMIO instances for the FractionatingColumnBottom is shown in Fig. 7.

\subsection{Automated Reasoning}

The instances, as well as their related attributes and relations, are implemented in Protégé. To determine the credible DMs for the fractionating column, SWRL rules are evaluated by running the rule engine. Fig. 8 depicts the asserted attributes and relations for the instance FractionatingColumnBottom. Based on the attributes, relations, axioms, and SWRL rules, it can be inferred that FractionatingColumnBottom has Sulfidation as its credible DM.

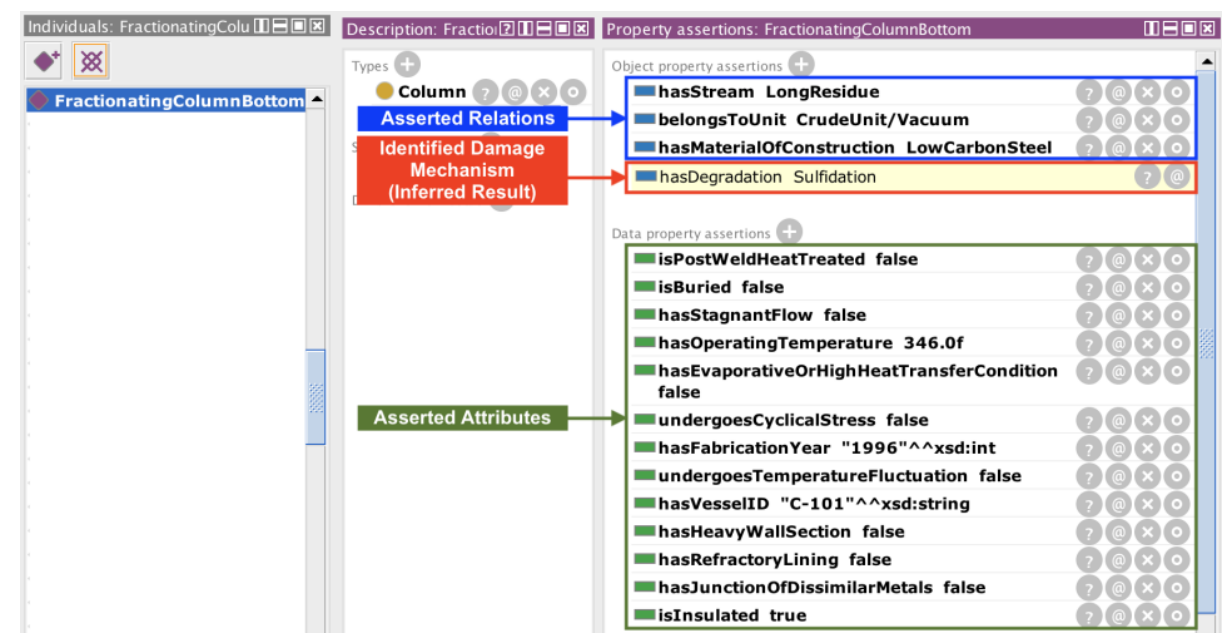

Fig. 8. The identified DM based on the automated reasoning for FractionatingColumnBottom

\section{Discussion}

In the DMIO approach, the domain knowledge related to DMs is conceptualized into ontology classes, relations, attributes, axioms, and rules, in order to enable automated 
reasoning and the identification of DMs in processing equipment. Hence, the DMA process can reduce its reliance on the assumptions, beliefs, and knowledge of engineering personnel. The case study shows that the factors and constraints that influence the occurrence of DMs in the processing equipment are grounded on logic theory, such that semantic reasoning can be used to support the identification of credible DMs [16]. The case study only shows DMIO application on a processing equipment part. In practice, DMA is generally performed on thousands of equipment parts. This is the circumstance in which the benefits of DMIO will be more noticeable.

In manual DMA, the basis of performing DMA (i.e., assumptions, understanding, rules, etc.) is retained in the heads of personnel who perform the assessment. In contrast, DMIO provides an explicit documentation regarding the basis of performing DMA, which ensures the consistency and validity of the assessment results. Moreover, all concepts related to DMs are defined unambiguously and consistently in DMIO. This prevents data mismatch and inconsistency and, thus, improves collaboration and information exchange among parties involved in the overall DMA process.

This study focuses only on the DMs' definitions stated in API 571, but the ontologybased semantic modeling approach can also be used on the DMs' concepts defined by other guidelines. Furthermore, because DMIO's development is based on the knowledge acquired from API 571 and API 581, it is applicable to broad categories of process industries (e.g., refineries, petrochemicals, and oil and gas).

\section{Conclusion}

This study discusses the utilization of ontology-based semantic modeling to facilitate the automated identification of DMs in process plant equipment and to enable the unambiguous communication and synchronization of perspectives among collaborating teams involved in the overall DMA process. The DMIO is proposed to represent concepts, relations, attributes, and instances relevant to DM knowledge. Supported by OWL axioms and SWRL rules, the DMIO is the foundation for performing automated reasoning in identifying credible DMs in process equipment. To demonstrate the application of DMIO in a real case, a case study of DM identification in a fractionating column in a refinery is given. The proposed approach is demonstrated in Protégé 5.2.0, based on the knowledge acquired from API 571 and API 581. The result of this study is applicable within the scope of API 571 and API 581, which is the process industries.

This study proves that an ontological and semantic approach can be used to reduce the cognitive load of engineering personnel in performing DMA, reducing the human biases and subjectivity inherent in DMA, cutting the lead-time for performing DMA, and improving collaboration and information exchange among parties involved in the overall DMA process.

Acknowledgment. This work has been carried out as part of a Ph.D. research project at the University of Stavanger, funded by the Norwegian Ministry of Education and Research. 


\section{References}

1. American Petroleum Institute: Risk-Based Inspection Methodology: API Recommended Practice 581 (3rd ed.). American Petroleum Institute, Washington, D.C. (2016)

2. Singh, M., Pokhrel, M.: A fuzzy logic-possibilistic methodology for risk-based inspection (RBI) planning of oil and gas piping subjected to microbiologically influenced corrosion (MIC). International Journal of Pressure Vessels and Piping 159, 45-54 (2018)

3. American Petroleum Institute: Risk-Based Inspection: API Recommended Practice 580 (3rd ed.). American Petroleum Institute, Washington, D.C. (2016)

4. Lintern, G.: The airspace as a cognitive system. The International Journal of Aviation Psychology 21, 3-15 (2011)

5. Frolov, V., Mengel, D., Bandara, W., Sun, Y., Ma, L.: Building an ontology and process architecture for engineering asset management. pp. 86-97. Springer London (2010)

6. Rajpathak, D., Chougule, R.: A generic ontology development framework for data integration and decision support in a distributed environment. International Journal of Computer Integrated Manufacturing 24, 154-170 (2011)

7. Batres, R., Fujihara, S., Shimada, Y., Fuchino, T.: The use of ontologies for enhancing the use of accident information. Process Safety and Environmental Protection 92, 119-130 (2014)

8. Batres, R., West, M., Leal, D., Price, D., Masaki, K., Shimada, Y., Fuchino, T., Naka, Y.: An upper ontology based on ISO 15926. Computers \& Chemical Engineering 31, 519-534 (2007)

9. Kim, B.C., Jeon, Y., Park, S., Teijgeler, H., Leal, D., Mun, D.: Toward standardized exchange of plant 3D CAD models using ISO 15926. Computer-Aided Design 83, 80-95 (2017)

10. Rajsiri, V., Lorré, J.-P., Bénaben, F., Pingaud, H.: Knowledge-based system for collaborative process specification. Computers in Industry 61, 161-175 (2010)

11. Fernández-López, M., Gómez-Pérez, A., Juristo, N.: METHONTOLOGY: From Ontological Art Towards Ontological Engineering. AAAI-97 Spring Symposium Series. American Association for Artificial Intelligence, Stanford University, EEUU (1997)

12. American Petroleum Institute: API Recommended Practice 571: Damage Mechanisms Affecting Fixed Equipment in the Refining Industry (2nd ed.). American Petroleum Institute (2011)

13. Lopez, M.F., Gomez-Perez, A., Sierra, J.P., Sierra, A.P.: Building a chemical ontology using methontology and the ontology design environment. IEEE Intelligent Systems and their Applications 14, 37-46 (1999)

14. Musen, M.A.: The protégé project: a look back and a look forward. AI Matters 1, 4-12 (2015)

15. Horrocks, I., Patel-Schneider, P.F., Boley, H., Tabet, S., Grosof, B., Dean, M.: SWRL: A semantic web rule language combining OWL and RuleML. W3C Member Submission 21, $79(2004)$

16. Zhong, B.T., Ding, L.Y., Luo, H.B., Zhou, Y., Hu, Y.Z., Hu, H.M.: Ontology-based semantic modeling of regulation constraint for automated construction quality compliance checking. Automation in Construction 28, 58-70 (2012)

17. Zhang, S., Boukamp, F., Teizer, J.: Ontology-based semantic modeling of construction safety knowledge: Towards automated safety planning for job hazard analysis (JHA). Automation in Construction 52, 29-41 (2015) 